\title{
Baseline susceptibility of Philippine Ostrinia furnacalis (Lepidoptera: Crambidae) populations to insecticidal Cry1A.105 and Cry2Ab2 proteins and validation of candidate diagnostic concentration for monitoring resistance
}

\author{
EDWIN P. ALCANTARA ${ }^{1, \vartheta}$, MARNELLE M. ATIENZA ${ }^{1}$, LUIS CAMACHO ${ }^{1}$, SRINIVAS PARIMI $^{2}$ \\ ${ }^{1}$ National Institute of Molecular Biology and Biotechnology, University of the Philippines. Los Baños, College, Laguna 4031, Philippines. \\ Tel./fax.: +63-49-536-2721, `email: epalcantara@up.edu.ph \\ ${ }^{2}$ Monsanto India Ltd., Lalgadi Malakpet, Telangana 500078, India
}

Manuscript received: 6 November 2020. Revision accepted: 22 January 2021.

\begin{abstract}
Alcantara EP, Atienza MM, Camacho L, Parimi S. 2021. Baseline susceptibility of Philippine Ostrinia furnacalis (Lepidoptera: Crambidae) populations to insecticidal CrylA.105 and Cry2Ab2 proteins and validation of candidate diagnostic concentration for monitoring resistance. Biodiversitas 22: 956-960. This study estimated the baseline susceptibility of Ostrinia furnacalis populations from the Philippines, to purified insecticidal Cry1A.105 and Cry2Ab2 proteins and determined a diagnostic concentration (DC) through a validation experiment. The insect populations were collected from separate sites of corn farms in Northern and Central Luzon and in South Cotabato province of the island of Mindanao. Dose-response bioassays using artificial diet surface overlay method were conducted on eight populations. The bioassay results revealed that the LC50 of Cry1 A.105 and Cry2Ab2 to $O$. furnacalis ranged from $0.03 \mathrm{ng} / \mathrm{cm} 2$ to $0.18 \mathrm{ng} / \mathrm{cm} 2$ and $1.40 \mathrm{ng} / \mathrm{cm} 2$ to $9.98 \mathrm{ng} / \mathrm{cm} 2$, respectively. The relative susceptibility ratios between the most susceptible and most tolerant populations were 6-fold for Cry1 A.105 and about 7-fold for Cry2Ab2. The candidate diagnostic concentrations (DC) based on the LC99 were calculated using the baseline bioassay data for both Cry1A.105 and Cry2 Ab2. The validation was performed on populations from the same locations used in the baseline susceptibility assay and a reference strain to produce at least $99 \%$ mortality for each protein. Data showed that populations tested with Cry1A.105 produced average mortality of at least 99\% for the upper limit, while this was observed in the LC99 estimate for Cry2Ab2. The validated diagnostic concentration can be used for monitoring the resistance development of O. furnacalis exposed to Bt Corn, MON89034, in the Philippines.
\end{abstract}

Keywords: Baseline susceptibility, diagnostic concentration, Ostrinia furnacalis, MON 89034, insect resistance

\section{INTRODUCTION}

In the Philippines, the Asian corn borer (ACB), Ostrinia furnacalis (Guenee) is the most destructive pest of corn (Afidchao et al. 2013). It causes damage to leaves at the mid-whorl stage (Zhang et al. 2016). The corn stalks boring behavior of ACB larvae renders the application of insecticide sprays ineffective (Chen et al. 2013). Yield loss was previously reported to be in the range of $20 \%$ to $80 \%$ (Mutuc et al. 2011). The advent of transgenic Bacillus thuringiensis (Bt) corn technology in 2002 has offered corn farmers in the Philippines a viable alternative for the sustainable control of ACB (Mutuc et al. 2013). For instance, the adoption of single trait event MON 810 resulted in positive effects on yield and farmer welfare (Sanglestsawai et al. 2017). To date, no field-evolved ACB resistance to MON 810 has been reported in the country. Nonetheless, as a proactive measure to further delay resistance development with field deployment of a twotoxin Bt crop (Tabashnik et al. 2013), the second generation Bt corn, MON 89034, was approved in 2010 for commercial use (https://biotech.da.gov.ph). MON89034 is a pyramided transgenic corn event expressing two insecticidal proteins, Cry1A.105, and Cry2Ab2 which are both highly effective against key lepidopteran pests (Storer et al. 2012). Widespread adoption of MON89034 might lead to the potential evolution of ACB resistance development (Dively et al. 2017). Thus, it is essential to implement insect resistance management (IRM) to maintain the effectiveness of MON89034. Monitoring for resistance development is an important component of an effective IRM strategy (Bilbo et al. 2019). Monitoring enables the timely application of mitigating measures to contain the spread of resistance in the field (Kotey et al. 2017). The first step towards widescale resistance monitoring is to determine the baseline susceptibility of ACB populations to Cry1A.105 and Cry2Ab2 proteins.

It is important to establish baseline susceptibility to determine the degree of natural variation in the populations, which can then be used to distinguish the changes in susceptibility in target insect populations (Leite et al. 2018). Moreover, baseline susceptibility data can be used to generate candidate concentrations out of which a diagnostic concentration (DC) can be obtained through a validation experiment. The selected DC is useful for bioassays in monitoring resistance development across populations. The DC method has been successfully utilized for monitoring $\mathrm{ACB}$ resistance development to other 
transgenic Cry proteins in Bt corn (Alcantara et al. 2011; Li et al. 2020). The present study was conducted to estimate the baseline susceptibility of different geographic populations of $O$. furnacalis to Cry1A.105 and Cry2Ab2 proteins, which is measured as lethal response (i.e., $\mathrm{LC}_{50}$ ) and to validate the candidate DC of CrylA.105 and Cry2Ab2 proteins and select the DC for monitoring the development of ACB resistance to Bt corn MON 89034 in the Philippines.

\section{MATERIALS AND METHODS}

\section{Insect collection and laboratory rearing}

The insect collections were made during the period of 2010-2012. Egg masses of $O$. furnacalis were collected from underneath corn leaves. The collected egg masses were placed in a Petri dish layered with moist filter paper. Alternatively, older instar larvae were extracted from infested corn stalks. Field collected larvae were reared until pupation in the laboratory using an artificial diet. Pupae that had developed from the laboratory-reared larvae were placed in Petri plate and placed inside a cage. Adults that had emerged from the pupae were mass mated inside the cage. Neonate larvae $\left(\mathrm{F}_{1}\right)$ eclosing from field collected or from laboratory mass mated adults were used for doseresponse bioassays. When samples were insufficient, additional field collection of larvae and or pupae were conducted. The collections were reared in the laboratory until sufficient insects were available for bioassay. The insect collection sites are shown in Figure 1. Typically, 200 larvae or 50 egg masses were collected to constitute a single population. Neonate larvae $\left(\mathrm{F}_{1}\right)$ hatching from field collected egg masses or from egg masses of laboratory mass mated adults were used for dose-response bioassays.

\section{Bioassays}

Artificial diet surface overlay assays of Cry1A.105 and $\mathrm{Cry} 2 \mathrm{Ab} 2$ and data analysis were performed as per the methodology described in Alcantara et al. (2011). Approximately $1 \mathrm{ml}$ artificial diet was dispensed separately in $20 \mathrm{ml}$ drum-type glass vials. After the artificial diet has solidified in the vial, Cry protein (70 $\mu$ l of dilution) in carbonate buffer $\mathrm{pH} 9.5$ containing $0.1 \%$ Triton X-100 was evenly spread on the surface of the solidified diet. The surface of the artificial diet was air-dried for one hour, and one neonate ( $<24 \mathrm{~h}$ after hatching) larva was transferred into each vial. The control vials containing artificial diet were treated only with buffer containing $0.1 \%$ Triton $\mathrm{X}$ 100. For each bioassay, six to eight doses (including one control) of Cry protein were used, with each dose replicated at least three times. Sixteen neonate larvae were used for each replicate. Mortality was scored after seven days. Purified Cry1A.105 and Cry2Ab2 protein solutions were provided by Bayer Crop Science (Monsanto Company), St. Louis, USA. The relative susceptibility ratios were calculated as described by Han et al. (2014). Corrected mortality was applied using Abbot's formula (Abbot 1925) when applicable. The median lethal concentration $\left(\mathrm{LC}_{50}\right)$ and the corresponding slope were estimated by probit analysis. The differences in $\mathrm{LC}_{50}$ estimates were considered significant when $95 \%$ fiducial limits do not overlap. Using the generated dose mortality data from the baseline bioassay, candidate diagnostic concentrations (DC) based on the resulting $\mathrm{LC}_{99}$ were also calculated. The candidate DC (i.e., the lower limit of $\mathrm{LC}_{99}$, estimated $\mathrm{LC}_{99}$, the upper limit of $\mathrm{LC}_{99}$ ) of Cry1 A.105 and Cry2Ab2 proteins were determined from pooled baseline concentration-mortality data. These were tested on ACB populations collected in all sentinel sites and a reference population. The same bioassay protocol used for the baseline experiment was followed for the validation experiment using the candidate concentrations. Each concentration was replicated three times with 50 neonate larvae per replicate. Control vials were also prepared using 50 neonate larvae. Mortality was scored after seven days. The selected DC for Cry1A.105 and Cry2Ab2, respectively, were re-tested by using a larger number of neonate larvae from each population collected from the same sites. Control vials were prepared using 100 neonates for each setup. Mortality was also recorded after seven days.

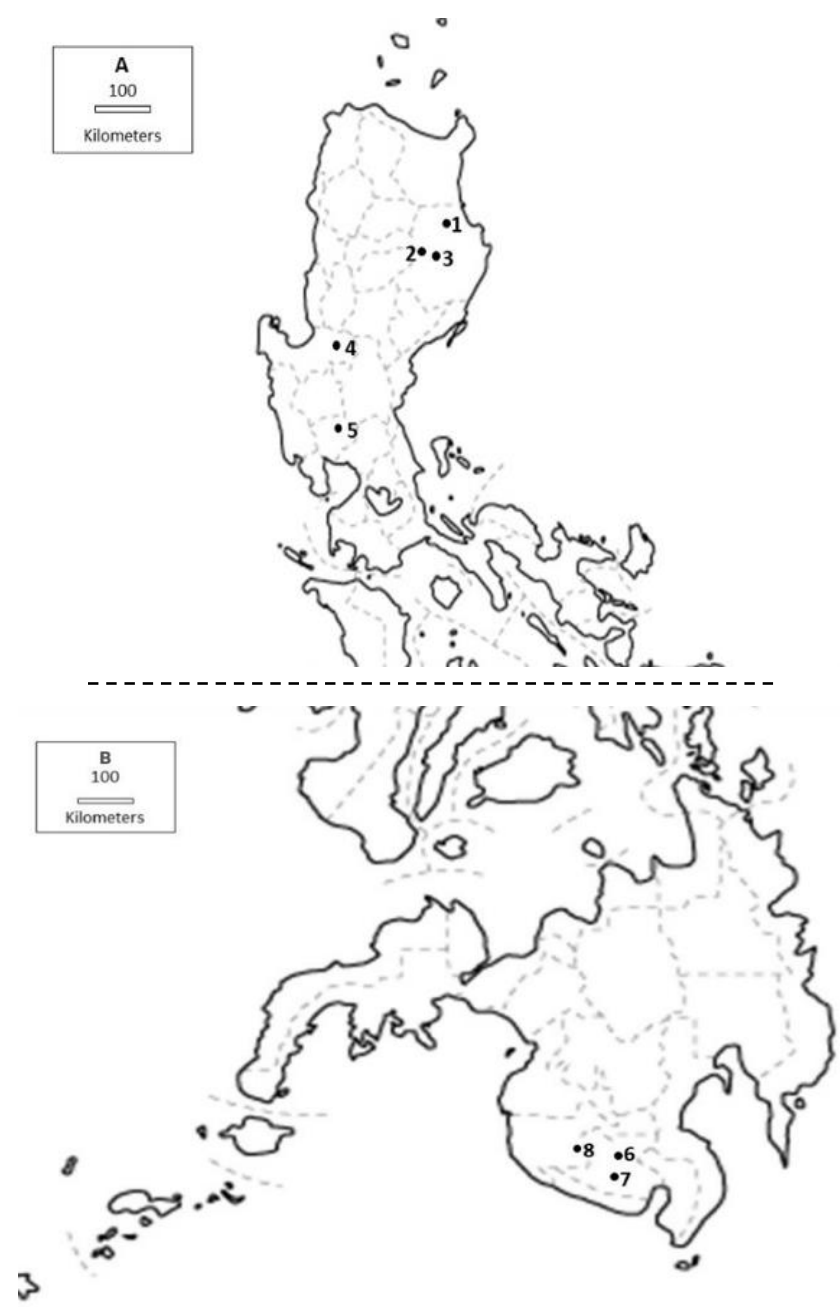

Figure 1. Location map of collection sites in Luzon (A) and Mindanao (B), Philippines. Location numbers correspond to the location numbers in tables 


\section{RESULTS AND DISCUSSION}

There is a need to develop a robust IRM strategy for MON89034 in the Philippines in order to prolong its durability in the field and, thus, avoid practical resistance (Tabashnik et al. 2014). The potential threat of fieldevolved resistance across several populations of ACB to MON89034 would be difficult to evaluate in the absence of data on baseline susceptibility of ACB to the two component Cry proteins (i.e., Cry1A.105 and Cry2Ab2) in MON89034. The baseline susceptibility data will reveal the extent of variation in response to the two MON89034 Cry proteins which in turn will provide clues in identifying ACB populations at higher risk of resistance development. These high-risk populations will, therefore, be prioritized for resistance monitoring. DC developed from pooled baseline susceptibility data will serve as a monitoring tool for timely detection of resistance development in ACB to MON89034.

\section{Toxicity to $O$. furnacalis}

In this study, several ACB populations were collected from representative corn farming locations where MON89034 is expected to be commercially distributed to farmers. The collected insects were utilized for laboratory bioassays to measure susceptibility to Cry1A.105 and Cry $2 \mathrm{Ab} 2$ proteins, respectively. Results of probit analysis of mortality data for $O$. furnacalis tested with purified Cry1A.105 are shown in Table $1 . \mathrm{LC}_{50}$ values ranged from $0.03 \mathrm{ng} / \mathrm{cm}^{2}$ to $0.18 \mathrm{ng} / \mathrm{cm}^{2}$. There were no significant differences in $\mathrm{LC}_{50}$ values observed across geographic populations of $O$. furnacalis. Furthermore, the $\mathrm{LC}_{50}$ values of the most susceptible and the most tolerant populations were 6-fold different. Results of probit analysis of mortality data for $O$. furnacalis tested with purified Cry2Ab2 are shown in Table $2 . \mathrm{LC}_{50}$ values ranged from $1.40 \mathrm{ng} / \mathrm{cm}^{2}$ to $9.98 \mathrm{ng} / \mathrm{cm}^{2}$. Significant differences in $\mathrm{LC}_{50}$ values were observed across geographic populations of $O$. furnacalis. Furthermore, the $\mathrm{LC}_{50}$ values of the most susceptible and the most tolerant populations were at least seven-fold different. The European corn borer, Ostrinia nubilalis, a close relative of $O$. furnacalis (Tan et al. 2011), has a similar degree of susceptibility with ACB to Cry1 A.105 but is less susceptible to Cry2Ab2 as compared to ACB (Hernandez-Rodriguez et al. 2013). The bioassay results further indicate that $O$. furnacalis populations are highly susceptible to Cry1A.105 and Cry2Ab2, respectively. The small variability in response to the toxins might also indicate the rarity of resistance alleles (Sumerford et al. 2013) in O. furnacalis. Naturally occurring minor geographical variability in Cry protein response in Ostrina spp. has also been reported (Le et al. 2019). It should also be noted that the laboratory bioassay procedure that was utilized in this study has been previously standardized to minimize experimental error and obtain consistent results from repeated bioassays. Jalali et al. (2014) observed large variations even in repeated assays of the same population of insects less sensitive to insecticidal Cry proteins. The insignificant $\chi^{2}$ values also indicate that there was a good fit of the data to the probit model used in the present study.

Table 1. Baseline susceptibility of Asian corn borer, Ostrinia furnacalis to Cry1 A.105 protein

\begin{tabular}{lccccccc}
\hline Collection site $^{\mathbf{a}}$ & Generation & $\mathbf{N}$ & Slope \pm SE & LC $_{\mathbf{5 0}}(\mathbf{9 5 \%} \mathbf{C I})$ & $\chi^{2}$ & df & Relative ratio \\
\hline Aurora (3) & F1 & 463 & $0.59 \pm 0.10$ & $0.14(0.086-0.24)$ & 2.14 & 7 & 4.67 \\
Cauayan (2) & F1 & 288 & $0.60 \pm 0.12$ & $0.09(0.04-0.17)$ & 1.25 & 7 & 3.00 \\
Tumauini (1) & F1 & 256 & $0.87 \pm 0.13$ & $0.03(0.01-0.05)$ & 2.99 & 6 & 1.00 \\
Sta Maria (4) & F1 & 432 & $0.49 \pm 0.09$ & $0.07(0.03-0.14)$ & 1.44 & 7 & 2.33 \\
Magalang (5) & F1 & 144 & $1.47 \pm 0.26$ & $0.03(0.001-0.04)$ & 7.87 & 7 & 1.00 \\
Banga (7) & F1 & 432 & $0.76 \pm 0.10$ & $0.13(0.08-0.20)$ & 2.49 & 7 & 4.33 \\
Bagumbayan (8) & F1 & 720 & $0.61 \pm 0.07$ & $0.08(0.05-0.12)$ & 3.79 & 7 & 2.67 \\
Koronadal (6) & F1 & 470 & $0.69 \pm 0.10$ & $0.18(0.11-0.28)$ & 1.51 & 6 & 6.00 \\
\hline
\end{tabular}

Note: ${ }^{\mathrm{a}}$ Numbers in brackets for each location are the location numbers in Figure 1

Table 2. Baseline susceptibility of Asian corn borer, Ostrinia furnacalis to Cry2Ab2 protein

\begin{tabular}{lccllccc}
\hline Collection Site $^{\mathbf{a}}$ & Generation & $\mathbf{N}$ & Slope \pm SE & LC $_{\mathbf{5 0}}(\mathbf{9 5 \%} \mathbf{C I})$ & $\boldsymbol{\chi 2}^{\mathbf{2}}$ & df & Relative ratio \\
\hline Aurora (3) & F1 & 204 & $0.75 \pm 0.15$ & $5.37(2.76-10.12)$ & 4.83 & 7 & 3.84 \\
Cauayan (2) & F1 & 256 & $0.495 \pm 0.12$ & $9.98(4.54-31.89)$ & 2.35 & 6 & 7.13 \\
Tumauini (1) & F1 & 224 & $0.81 \pm 0.14$ & $1.40(0.48-2.69)$ & 9.75 & 9 & 1.00 \\
Sta Maria (4) & F1 & 416 & $0.52 \pm 0.10$ & $1.90(0.84-3.41)$ & 3.35 & 7 & 1.36 \\
Magalang (5) & F1 & 288 & $0.98 \pm 0.13$ & $1.61(0.95-2.42)$ & 5.85 & 7 & 1.15 \\
Banga (7) & F1 & 560 & $0.59 \pm 0.08$ & $6.61(4.25-11.08)$ & 2.71 & 7 & 4.72 \\
Bagumbayan (8) & F1 & 288 & $0.82 \pm 0.12$ & $2.77(1.64-4.40)$ & 5.09 & 7 & 1.98 \\
Koronadal (6) & F1 & 272 & $0.62 \pm 0.13$ & $3.72(1.76-6.93)$ & 0.30 & 7 & 2.66 \\
\hline
\end{tabular}

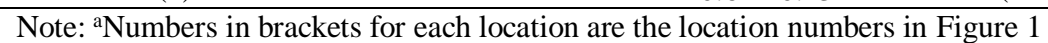




\section{Validation of diagnostic concentration}

The $\mathrm{LC}_{99}$ estimates derived from probit analysis of pooled mortality data were chosen to develop a DC for both Cry proteins. DC is one of the useful available tools for future implementation of resistance monitoring programs (Bentivenha et al. 2019). All ACB populations tested were highly susceptible to the upper limit of the $\mathrm{LC}_{99}$ of both proteins, with an average mortality of at least $99 \%$. For Cry1A.105 using the three candidates DCs, the Cauayan population is observed to be less susceptible to the lower limit of the $\mathrm{LC}_{99}$ estimate (i.e., $40 \mathrm{ng} / \mathrm{cm}^{2}$ ). A similar susceptibility pattern can be observed in the reference susceptible population. There were significant differences between the geographic populations and within the treatment used when the data were subjected to analysis of variance. Moreover, using a lower-tailed Z-test to test the significance $(\alpha=0.05)$ of each resulting mean mortality data lower than the expected $99 \%$, mean mortality of the two populations (Table 3) are significantly lesser than the rest in the lower limit of Cry1A.105. The bioassay data suggest that the upper limit of the $\mathrm{LC}_{99}$ estimate can be used as DC for monitoring. A similar susceptibility pattern was observed in all the ACB populations when tested with the three candidate $\mathrm{DC}$ of insecticidal $\mathrm{Cry} 2 \mathrm{Ab} 2$ protein. However, there were no significant differences across the geographic populations and the concentrations tested. Average mortality values ranged from $96 \%$ to $100 \%$, and only one population (Table 4) was significantly lesser than 99\%. The ACB populations were relatively highly susceptible for both the $\mathrm{LC}_{99}$ and the upper dosage limit. The bioassay data suggest that the $\mathrm{LC}_{99}$ estimate (i.e., 1,700 $\mathrm{ng} / \mathrm{cm}^{2}$ ) could be selected as DC for monitoring ACB resistance to $\mathrm{Cry} 2 \mathrm{Ab} 2$ protein. Bioassays using the selected DC for both Cry proteins resulted in one hundred percent mortality in all the populations tested (Table 5), validating that the selected DC can result in at least $99 \%$ mortality.

Results of the validation experiment show that there are significant differences observed among $O$. furnacalis populations when 3 candidate diagnostic concentrations of CrylA.105 were used. The mean mortality data of Cry1A.105 suggest that the upper limit of the $\mathrm{LC}_{99}$ (i.e., $164 \mathrm{ng} / \mathrm{cm}^{2}$ ) could be selected as DC for monitoring ACB resistance to Cry1A.105 in the Philippines. Two populations (i.e., Cauayan and Los Baños) resulted in mean mortality of $<99 \%$ in the lower dose limit, implying that a higher concentration than the LC99 must be considered to produce the least $99 \%$ mortality in the populations. Moreover, there is no significant difference observed when three candidate diagnostic concentrations of Cry2Ab2 protein are used. One (i.e., Cauayan) out of eight populations has mean mortality of $<99 \%$, with a significant difference from the expected. Since all the populations are relatively susceptible to the three candidate diagnostic doses, the $\mathrm{LC}_{99}$ estimate could be used as DC for monitoring resistance to Cry2Ab2 in the Philippines. To ensure that the selected concentration is appropriate, the selected DC for both Cry proteins were tested on a larger number of samples from selected collection sites. The number of selected collection sites was less than the original number of sites used for the baseline study. Current resistance monitoring efforts are re-focused on "hotspot" areas where Bt corn is continuously planted. The high selection pressure in these hotspot areas might create the condition for rapid resistance development in ACB, hence testing the DC was focused on these hotspot areas.

Table 3. Validation of the estimated LC 99 of Cry1A.105 with eight populations of the Asian corn borer. The three concentrations are the lower limit of $\mathrm{LC}_{99}$, $\mathrm{LC}_{99}$, and upper limit of $\mathrm{LC}_{99}$ as estimated by probit analysis of pooled bioassay data

\begin{tabular}{lcccc}
\hline \multirow{2}{*}{ Population } & $\mathbf{N}^{\mathbf{1}}$ & \multicolumn{4}{c}{$\mathbf{4 0}$ Mean mortality } \\
\cline { 3 - 5 } & & $\mathbf{4 0} / \mathbf{c m}^{\mathbf{2}}$ & $\begin{array}{c}\mathbf{8 1} \\
\mathbf{n g} / \mathbf{c m}^{\mathbf{2}}\end{array}$ & $\begin{array}{c}\mathbf{1 6 4} \\
\mathbf{n g} / \mathbf{c m}^{\mathbf{2}}\end{array}$ \\
\hline Banga, South Cotabato & 150 & 100 & 100 & 100 \\
Koronadal, South Cotabato & 150 & 100 & 100 & 100 \\
Sta. Maria, Pangasinan & 150 & $99.33 \pm 0.67$ & 100 & 100 \\
Arayat, Pampanga & 150 & 100 & 100 & 100 \\
Cauayan, Isabela & 150 & $86.67 \pm 10.93 *$ & 100 & 100 \\
Aurora, Isabela & 150 & 100 & 100 & 100 \\
Tumauini, Isabela & 150 & 100 & 100 & 100 \\
Los Baños & 150 & $64.67 \pm 8.17^{*}$ & 100 & 100 \\
\hline
\end{tabular}

Note: $\mathrm{N}^{1}=$ total population with 3 replications, ${ }^{*}=$ significantly < $99 \%$

Table 4. Validation of the estimated LC99 of Cry2Ab2 with eight populations of the Asian corn borer. The three concentrations are the lower limit of $\mathrm{LC}_{99}, \mathrm{LC}_{99}$, and upper limit of $\mathrm{LC}_{99}$ as estimated by probit analysis of pooled bioassay data. ${ }^{1}$

\begin{tabular}{|c|c|c|c|c|}
\hline \multirow[b]{2}{*}{ Population } & \multirow[b]{2}{*}{$\mathbf{N}^{1}$} & \multicolumn{3}{|c|}{ \% Mean mortality } \\
\hline & & $\begin{array}{c}854 \\
\mathrm{ng} / \mathrm{cm}^{2}\end{array}$ & $\begin{array}{c}1704 \\
\mathrm{ng} / \mathrm{cm}^{2}\end{array}$ & $\begin{array}{c}3500 \\
\mathrm{ng} / \mathrm{cm}^{2}\end{array}$ \\
\hline Banga, South Cotabato & 150 & 100 & 100 & 100 \\
\hline Koronadal, South Cotabato & 150 & $99.33 \pm 0.67$ & 100 & 100 \\
\hline Sta. Maria, Pangasinan & 150 & 100 & 100 & 100 \\
\hline Arayat, Pampanga & 150 & 100 & 100 & 100 \\
\hline Cauayan, Isabela & 150 & $96 \pm 4.00^{*}$ & 100 & 100 \\
\hline Aurora, Isabela & 150 & $99.33 \pm 0.67$ & 100 & 100 \\
\hline Tumauini, Isabela & 150 & 100 & 100 & 100 \\
\hline Los Baños & 150 & 100 & 100 & 100 \\
\hline
\end{tabular}

Note: $\mathrm{N}^{1}=$ total population with 3 replications, ${ }^{*}=$ significantly $<$ $99 \%$

Table 5. Mortality of Philippine populations of Asian corn borer at a diagnostic concentration of Cry1 A. 105 and Cry2 Ab2 proteins

\begin{tabular}{|c|c|c|c|c|}
\hline \multirow[b]{2}{*}{ Population } & \multicolumn{4}{|c|}{ \% Mean mortality } \\
\hline & $\mathbf{N}$ & $\begin{array}{l}\text { Cry1A.105 } \\
\left(164 \text { ng/cm }{ }^{2}\right)\end{array}$ & $\mathbf{N}$ & $\begin{array}{c}\text { Cy2Ab2 } \\
\left(1704 \mathrm{ng} / \mathrm{cm}^{2}\right)\end{array}$ \\
\hline Banga, South Cotabato & 150 & 100 & 100 & 100 \\
\hline Koronadal, South Cotabato & 150 & 100 & 100 & 100 \\
\hline Sta. Maria, Pangasinan & 150 & 100 & 100 & 100 \\
\hline Arayat, Pampanga & 150 & 100 & 100 & 100 \\
\hline Cauayan, Isabela & 150 & 100 & 100 & 100 \\
\hline Aurora, Isabela & 150 & $99.33 \pm 0.67$ & 100 & 100 \\
\hline Tumauini. Isabela & 150 & 100 & 100 & 100 \\
\hline Los Baños & 150 & 100 & 100 & 100 \\
\hline
\end{tabular}


The resulting data of 100 percent mortality for all the populations assayed using the two Cry proteins support the previous bioassay results that the selected diagnostic concentration can be used for annual monitoring for resistance development. Specifically, in the future monitoring program, the increase in the frequency of nonrecessive resistance should be closely monitored because it is a significant factor in determining the trajectory of fieldevolved resistance (Zhang et al. 2012). The results presented in this study are the first for $O$. furnacalis in the Philippines and lays the ground for implementing a sound resistance monitoring program to routinely evaluate the susceptibility changes in this insect pest when exposed to MON 89034 products expressing Cry1A.105 and Cry2Ab2 insecticidal proteins.

\section{ACKNOWLEDGEMENTS}

Funding for this study was provided by Monsanto Philippines, Inc. This study does not contain any experiments with human participants or any other vertebrates.

\section{REFERENCES}

Afidchao M, Musters CJ, de Snoo GR. 2013. Asian corn borer (ACB) and non-ACB pests in GM corn (Zea mays L.) in the Philippines. Pest Manag Sci 69 (7): 792-801. DOI: 10.1002/ps.3471.

Alcantara EP, Estrada A, Alpuerto V, Head G. 2011. Monitoring Cry1 Ab susceptibility in Asian corn borer (Lepidoptera: Crambidae) on B corn in the Philippines. Crop Prot 30: 554-559. DOI: 10.1016/j.cropro.2010.12.019.

Bentivenha JP, Rodrigues JG, Lima MF, Marcon P, Popham HJ, Omoto C. 2019. Baseline susceptibility of Spodoptera frugiperda (Lepidoptera: Noctuidae) to SfMNPV and Evaluation of crossresistance to major insecticides and Bt proteins. J Econ Entomol 112 (1): 91-98. DOI: 10.1093/jee/toy342.

Bilbo TR, Reay-Jones F, Reisig DD, Greene JK. 2019. Susceptibility of corn earworm (Lepidoptera: Noctuidae) to Cry1A.105 and Cry2Ab2 in North and South Carolina. J Econ Entomol 112 (4): 1845-1857. DOI: $10.1093 /$ jee/toz062.

Chen RZ, Klein MG, Sheng CF, Li Y, Shao DX, Li QY. 2013. Use of pheromone timed insecticide applications integrated with mating disruption or mass trapping against Ostrinia furnacalis (Lepidoptera: Pyralidae) in sweet corn. Environ Entomol 42 (6): 1390-1399. DOI: $10.1603 / \mathrm{EN} 13143$

Dively GP, Venugopal PD, Finkenbinder C. 2017. Field-evolved resistance in corn earworm to Cry proteins expressed by transgenic sweet corn. PLoS One 11 (12): e0169115. DOI: 10.1371/journal.pone.0169115.

Han L, Han C, Liu Z, Chen F, Jurat-Fuentes JL, Hou M, Peng Y. 2014 Binding Site Concentration Explains the Differential Susceptibility of Chilo suppressalis and Sesamia inferens to Cry1 A-Producing Rice.
Appl Environ Microbiol 80 (16): 5134-5140. DOI: 10.1128/AEM.01544-14.

Hernandez-Rodriguez C, Hernandez-Martinez P, Van Rie J, Escriche B, Ferre J. 2013. Shared midgut binding sites for Cry1A.105, Cry1Aa, Cry1 Ab, Cry1 Ac and Cry1Fa proteins from Bacillus thuringiensis in two important corn pests, Ostrinia nubilalis and Spodoptera frugiperda. PLoS One 8 (7): e68164. DOI: 10.1371/journal.pone.0068164.

Jalali SK, Yadavalli L, Ojha R, Kumar P, Sulaikhabeevi SB, Sharma R, Nair R, Kadanur RC, Kamath SP, Komarlingam MS. 2014. Baseline sensitivity of maize borers in India to the Bacillus thuringiensis insecticidal proteins Cry1 A.105 and Cry2Ab2. Pest Manag Sci 71 (8): 1082-1090. DOI: $10.1002 /$ ps.3888.

Kotey DA, Obi A, Assefa Y, Erasmus A, Van den Berg A. 2017. Monitoring resistance to Bt maize in field populations of Busseola fusca (Fuller) (Lepidoptera: Noctuidae) from smallholder farms in the Eastern Cape province in South Africa. Afr Entomol 25 (1): 200-209.

Le DK, Le QK, Tran TTH, Nguyen DV, Dao TH, Nguyen TT, Truong XL, Nguyen QC, Pham HP, Phan TTT, Baktavachalam GB. 2019. Baseline susceptibility of Asian corn borer (Ostrinia furnacalis (Guenee)) populations in Vietnam to Cry1 Ab insecticidal protein. J Asia-Pac Entomol 22: 493-498. DOI: 10.1016/j.aspen.2019.02.010

Leite NA, Pereira RM, Durigan MR, Amado D, Fatoretto J, Medeiros FCL, Omoto C. 2018. Susceptibility of Brazilian populations of Helicoverpa armigera and Helicoverpa zea (Lepidoptera: Noctuidae) to Vip3Aa20. J Econ Entomol 111 (1): 399-404. DOI: 10.1093/jee/tox336.

Li GP, Huang JR, Ji TJ, Tian CH et al. 2020. Baseline susceptibility and resistance allele frequency in Ostrinia furnacalis related to Cry1 toxins in the Huanghuaihai summer corn region of China. Pest Manag Sci 76 (12): 4311-4317. DOI: 10.1002/ps.5999.

Mutuc M, Rejesus RM, Yorobe JM. 2011. Yields, insecticide productivity, and Bt corn: Evidence from damage abatement models in the Philippines. AgBioForum 14 (2): 35-46.

Mutuc M, Rejesus RM, Yorobe JM. 2013. Which farmers benefit the most from Bt corn adoption? Estimating heterogeneity effects in the Philippines. Agric Econ 44 (2): 231-239. DOI: 10.1111/agec.12006.

Sanglestsawai S, Rodriguez DP, Rejesus RM, Yorobe JM. 2017. Production risk, farmer welfare, and Bt corn in the Philippines. Agric Res Econ Rev 46 (3): 507-528.

Storer NP, Thompson GD, Head GP. 2012. Application of pyramided traits against Lepidoptera in insect resistance management for $\mathrm{Bt}$ crops. GM Crops Food 3 (3): 154-162. DOI: 10.4161/gmcr.20945

Tabashnik BE, Brevault T, Carrierre Y. 2013. Insect resistance to Bt crops: lessons from the first billion acres. Nat Biotechnol 31 (6): 510521. DOI: $10.1038 /$ nbt. 2597.

Tabashnik BE, Mota-Sachez D, Whalon ME, Hollingworth RM, Carriere Y. 2014. Defining terms for proactive management of resistance to $\mathrm{Bt}$ crops and pesticides. J Econ Entomol 107 (2): 496-507. DOI: $10.1603 / \mathrm{ec} 13458$

Tan SY, Cayabyab BF, Alcantara EP, Ibrahim YB, Huang F, Blankenship EE, Siegfried BD. 2011. Comparative susceptibility of Ostrinia furnacalis, Ostrinia nubilalis and Diatraea saccharalis (Lepidoptera: Crambidae) to Bacillus thuringiensis Cry1 toxins. Crop Prot 30: 1184-1189. DOI: 10.1016/j.cropro.2011.05.009.

Zhang H, Tian W, Zhao J, Jin L, et al. 2012. Diverse genetic basis of field-evolved resistance to Bt cotton in cotton bollworm from China. Proc Natl Acad Sci USA 109 (26): 10275-10280.

Zhang TT, He K, Wang, ZY. 2016. Transcriptome comparison analysis of Ostrinia furnacalis in four developmental stages. Sci Rep 6: 35008. DOI: 10.1038/srep35008. 